\title{
Is a change in mode of travel to school associated with a change in overall physical activity levels in children? Longitudinal results from the SPEEDY study
}

\author{
Lee Smith ${ }^{1,2}$, Shannon Sahlqvist ${ }^{1,2}$, David Ogilvie ${ }^{1,2}$, Andy Jones ${ }^{3}$, Kirsten Corder ${ }^{2}$, Simon J Griffin ${ }^{1,2}$
} and Esther van Sluijs ${ }^{1,2^{*}}$

\begin{abstract}
Background: Children who use active modes of travel (walking or cycling) to school are more physically active than those who use passive (motorised) modes. However, less is known on whether a change in mode of travel to school is associated with a change in children's physical activity levels. The purpose of this analysis was to investigate the association between change in mode of travel to school and change in overall physical activity levels in children.

Methods: Data from 812 9-10 year old British children (59\% girls) who participated in the SPEEDY study were analysed. During the summer terms of 2007 and 2008 participants completed a questionnaire and wore an accelerometer for at least three days. Two-level multiple linear regression models were used to explore the association between change in usual mode of travel to school and change in objectively measured time spent in MVPA.

Results: Compared to children whose reported mode of travel did not change, a change from a passive to an active mode of travel was associated with an increase in daily minutes spent in MVPA (boys: beta 11.59, 95\% Cl 0.94 to 22.24 ; girls: beta $11.92,95 \% \mathrm{Cl} 5.00$ to 18.84 ). This increase represented $12 \%$ of boys' and $13 \%$ of girls' total daily time spent in MVPA at follow-up.
\end{abstract}

Conclusion: This analysis provides further evidence that promoting active travel to school may have a role in contributing to increasing physical activity levels in children.

Keywords: Transport, Active travel, Physical activity, School children

\section{Background}

Physical activity is known to be positively associated with overall health in children [1,2]. Active travel provides an opportunity for children to incorporate physical activity into their daily lives and has been shown to be associated with health outcomes. For example, a systematic review identified nine high quality studies of the association between walking and cycling (active travel) to

\footnotetext{
* Correspondence: esther.vansluijs@mrc-epid.cam.ac.uk

'MRC Epidemiology Unit, Institute of Metabolic Science, Addenbrooke's

Hospital, Box 285, Cambridge CB2 0QQ, UK

${ }^{2}$ UKCRC Centre for Diet and Activity Research (CEDAR), Institute of Public

Health, Forvie Site, Robinson Way, Cambridge CB2 OSR, UK

Full list of author information is available at the end of the article
}

school and weight status or body composition in young people, of which $55 \%$ demonstrated a significant inverse association [3]. However, the proportion of UK children walking to school has decreased since 1995 and now stands at less than $50 \%$ [4].

Cross-sectional studies identified in systematic reviews suggest that young people who walk or cycle to school can accumulate between 5 and 37 additional minutes per day (min/day) of moderate-to-vigorous physical activity (MVPA) compared to those who use motorised (passive) modes of transport [5,6]. Associations between walking or cycling to school and physical activity have been shown to differ by sex, although the evidence is

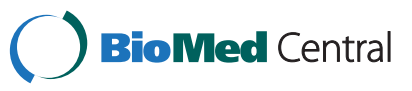

(c) 2012 Smith et al.; licensee BioMed Central Ltd. This is an Open Access article distributed under the terms of the Creative Commons Attribution License (http://creativecommons.org/licenses/by/2.0), which permits unrestricted use, distribution, and reproduction in any medium, provided the original work is properly cited. 
inconsistent. For example, Rosenberg et al. found stronger associations in boys than in girls [7] whereas Cooper et al. found an association only in girls [8]. Using crosssectional data from the Sport Physical Activity and Eating Behaviour: Environmental Determinants in Young People (SPEEDY) study, Panter et al. found that girls and boys who walked to school spent an additional $6.9 \mathrm{~min} /$ day and $3.3 \mathrm{~min} /$ day, respectively, in overall MVPA compared to those who used passive modes of transport. Girls and boys who cycled to school spent an additional $3.7 \mathrm{~min} /$ day and $6.5 \mathrm{~min} /$ day, respectively, in overall MVPA [9].

These findings suggest that active travel is associated with higher overall levels of physical activity $[5,6]$. However, given their cross-sectional nature it is difficult to establish the direction of causality. More importantly from a public health perspective, it remains unclear whether changing from a passive to an active mode of travel is necessarily associated with an increase in overall physical activity. It is possible that children might compensate for a change to an active mode of travel with a decrease in other forms of physical activity (activity compensation) $[10,11]$. On the other hand, a previous study investigated the association between taking up cycling to school and cardiorespiratory fitness over a sixyear follow-up showed that taking up cycling to school was a significant predictor of increased cardiorespiratory fitness at follow-up [12]. One possible explanation is that taking up cycling to school may have increased participants' overall physical activity levels and thus cardiorespiratory fitness. Alternatively participants who became more physically active in general between baseline and follow-up, and therefore improved their cardiorespiratory fitness, may then have taken up cycling to school.

In order to assess the potential role of active travel for increasing population levels of physical activity, it is important to investigate whether the above association can be found when using physical activity rather than fitness as an outcome. We therefore investigated the association between change in mode of travel to school and change in objectively measured physical activity over a one-year period in 9-10 year old British school children taking part in the SPEEDY study.

\section{Methods}

Full details of participant recruitment and study procedures are provided elsewhere [13,14]. In brief, the SPEEDY study is a prospective population-based cohort study examining factors associated with physical activity and dietary behaviour in pupils aged 9-10 years (at baseline) sampled through schools in the county of Norfolk, UK. A total of 157 schools were approached, of which 92 (59\%) agreed to participate. All Year 5 (9-10 years old) pupils in these schools $(\mathrm{n}=3619)$ were invited and a participation rate of $57 \%(\mathrm{n}=2064)$ was achieved. Two waves of data collection were carried out during the summer terms (April to July) of 2007 and 2008. At baseline, both pupils and their parents were asked to complete separate questionnaires about the pupils' dietary and physical activity behaviour. Pupils were also asked to complete an additional questionnaire at followup. At both time points pupils were asked to wear an Actigraph accelerometer (GTIM, Actigraph LCC, Pensacola, US) for seven consecutive days. Accelerometers were programmed to store activity data at five second intervals. Questionnaires and accelerometers were administered at the same point in time at baseline (by research staff directly) and at follow-up (by post) in an attempt to maximise coherence between measures. Written parental consent was obtained prior to data collection and ethical approval was granted by the University of East Anglia research ethics committee.

\section{Exposure measure}

To assess travel behaviour, pupils answered the same question at both time points: 'How do you usually travel to school?' Children were asked to indicate the main travel mode used: (a) car, (b) bus or train, (c) walk, or (d) bike (cycle). Use of the car, bus, or train was defined as 'passive travel' and walking and cycling were defined as 'active travel', consistent with other studies of the relationship between travel mode and physical activity $[7,8]$. Depending on their responses to this question at both time points, pupils were categorised into one of four exposure categories: 1) 'consistent active travel', 2) 'consistent passive travel', 3) 'change from passive to active travel' and 4) 'change from active to passive travel'.

\section{Outcome measures}

Accelerometer data were cleaned using a standard program (available at www.mrc-epid.cam.ac.uk). All data collected between 2300 and 0600 hours were removed as well as data from the first day (a partial wear day) because of the wide range of times at which participants received their accelerometer. Ten minutes of continuous zero counts were classified as 'non-wear time', which amounted to an average of five hours of non-wear time per participant per day. Accelerometer data were summarised as time (min/day) spent in MVPA where MVPA was defined as $\geq 2000$ counts per minute, a cut point applied in previous studies in this age group [15]. To explore any differences in physical activity levels by weekdays and weekends, time spent in MVPA was aggregated into the following two summary periods: (i) weekday MVPA (Monday to Friday between 0600 and 2300) and (ii) total daily MVPA (weekdays and weekend days between 0600 and 2300). To be included in the weekday analysis, three or more valid weekdays (wear 
time $\geq 500 \mathrm{~min} /$ day) of data were required at both baseline and follow-up. To be included in the total daily analysis, three or more valid weekdays or weekend days of data were required at both baseline and follow-up. The choice of a three-day criterion reflected adequate reliability of the accelerometry measures across three or more valid wear days in this dataset (intraclass correlation coefficient $=0.78$ ).

To assess whether change in mode of travel between baseline and follow-up was associated with change in physical activity, and to allow results to be expressed in a meaningful metric, the difference in the number of minutes spent in MVPA between baseline and follow-up was calculated for each participant for both weekday and total daily analysis. To account for any difference in accelerometer wear time between the two measurement periods, the change in time spent in MVPA was calculated for every 1000 minutes of wear time as follows: (1year follow-up MVPA x 1000/1-year follow-up wear time) - (baseline MVPA x 1000/baseline wear time). The constant of 1000 was chosen as it is approximately equal to the highest observed daily accelerometer wear time in the dataset (1053 min) and corresponds to a reasonable maximum realistic daily wear time in this age group ( 17 hours).

\section{Covariates}

At baseline pupils reported their sex and age, and their parent or main carer reported household car ownership and their own highest educational qualification (in categories). Objective measures of urban/rural status and network distance from home to school (based on home postcode) were estimated using a Geographic Information System [16]. Trained research assistants measured pupils' height and weight (whilst children wore light clothing) according to standard operating procedures from which body mass index (BMI) was calculated in $\mathrm{kg} / \mathrm{m}^{2}$. These covariates were selected because they were hypothesised to be independently associated with both the exposure (change in travel behaviour) and the outcome (change in physical activity).

\section{Analysis}

Characteristics of the study population at baseline and follow-up were summarised using descriptive statistics. To assess whether change in mode of travel was associated with change in physical activity, two-level linear regression models were used with pupils at level 1 and school at level 2, to account for the clustering of outcomes amongst children within the same schools. The outcomes were change in average weekday time spent in MVPA and change in average total daily time spent in MVPA (computed as described above). The exposure was change in travel mode (categorised as described above). Next, pre-specified covariates as well as baseline time spent in MVPA ( $\mathrm{min} /$ day) were entered into the models as potential confounders. To account for the well documented sex differences in the association between physical activity and active travel, [5,6] analyses were also stratified by sex.

\section{Results}

A total of 2064 pupils took part at baseline, of whom $55.1 \%$ were girls and $96.2 \%$ were white. Of the 1019 pupils who took part at follow-up, 954 returned an activity monitor. 812 pupils were entered into the weekday analyses owing to incomplete or missing MVPA $(n=96)$ or travel mode $(\mathrm{n}=46)$ data. The same 812 pupils were entered into total daily (weekdays plus weekend days) analyses. After excluding cases with missing data for potential confounders (predominantly parental education), final adjusted models included 772 pupils. There were no significant differences between the characteristics (sex, ethnicity, BMI, urban/rural status, parental education or baseline MVPA: all $p>0.05)$ of pupils who participated at baseline only $(\mathrm{n}=1244)$ and those included in the final adjusted models $(\mathrm{n}=772) .59 \%$ of pupils included in analyses were girls and $97 \%$ were white.

Table 1 shows participant demographics and frequency of travel mode at baseline and follow-up. At both time points, most pupils either walked or were driven to school. $40.6 \%(n=330)$ of pupils were categorised as reporting 'consistent passive travel' and $44.1 \%(\mathrm{n}=358)$ as reporting 'consistent active travel'. $6.1 \%$ of pupils $(\mathrm{n}=50)$ were categorised as having changed from an active to a passive mode of travel, and $9.2 \%(\mathrm{n}=75)$ from a passive to an active mode.

Pupils who changed their usual mode of travel did not differ significantly from the total study sample in terms of sex, ethnicity or home location. Table 2 shows that pupils who changed to an active mode of travel and those who changed to a passive mode recorded a mean total daily increase and decrease respectively in minutes spent in MVPA. Table 3 shows similar findings for change in mean weekday minutes spent in MVPA.

In two-level multiple linear regression analyses (Tables 4 and 5), change to an active mode of travel was positively associated with an increase in weekday and total daily time spent in MVPA compared with the reference category of 'consistent active travel'. This association remained after adjustment for potential confounders and was observed in boys and girls separately, with the exception of weekday MVPA for boys for which no significant association was found. No significant associations were found for other change in travel mode groups.

A total of 34 participants included in the analysis moved home between baseline and follow-up. These 
Table 1 Participant demographics and travel behaviour at baseline and follow-up

\begin{tabular}{|c|c|c|c|c|c|c|}
\hline \multirow[t]{2}{*}{ Variable } & \multicolumn{2}{|c|}{$\begin{array}{l}\text { Frequency in complete } \\
\text { baseline sample }\end{array}$} & \multicolumn{2}{|c|}{$\begin{array}{l}\text { Frequency in complete 1- } \\
\text { year follow-up sample }\end{array}$} & \multicolumn{2}{|c|}{$\begin{array}{c}\text { Frequency at 1-year follow-up among those who } \\
\text { had valid MVPA and travel mode data }\end{array}$} \\
\hline & \multicolumn{2}{|c|}{$\mathrm{N}(\%)$} & \multicolumn{2}{|c|}{$\mathrm{N}(\%)$} & \multicolumn{2}{|c|}{ N (\%) } \\
\hline Sex & \multicolumn{2}{|c|}{$\mathbf{n}=2064$} & \multicolumn{2}{|c|}{$\mathbf{n}=913$} & \multicolumn{2}{|c|}{$\mathbf{n}=812$} \\
\hline Boy & 926 & (45) & 374 & (41) & 333 & $(41)$ \\
\hline$\overline{\text { Girl }}$ & 1,138 & (55) & 539 & (59) & 479 & (59) \\
\hline Ethnicity & \multicolumn{2}{|c|}{$\mathbf{n}=1914$} & \multicolumn{2}{|c|}{$\mathbf{n}=885$} & \multicolumn{2}{|c|}{$\mathbf{n}=794$} \\
\hline White & 1841 & (96) & 857 & (97) & 770 & (97) \\
\hline Other & 73 & (4) & 28 & (3) & 24 & (3) \\
\hline Urban/rural status & \multicolumn{2}{|c|}{$\mathbf{n}=2023$} & \multicolumn{2}{|c|}{$\mathbf{n}=902$} & \multicolumn{2}{|c|}{$\mathbf{n}=802$} \\
\hline Hamlet and isolated dwelling & 142 & (7) & 73 & (8) & 67 & (8) \\
\hline Village & 506 & (25) & 248 & (28) & 219 & (27) \\
\hline Town and fringe & 575 & (28) & 275 & (30) & 244 & (30) \\
\hline Urban $>10 \mathrm{k}$ & 800 & $(40)$ & 306 & (34) & 272 & (34) \\
\hline Parent education status & \multicolumn{2}{|c|}{$\mathbf{n}=1882$} & \multicolumn{2}{|c|}{$\mathbf{n}=877$} & \multicolumn{2}{|c|}{$\mathbf{n}=786$} \\
\hline None & 140 & (7) & 53 & (6) & 45 & (6) \\
\hline GCSE or equivalent & 963 & (51) & 454 & (52) & 405 & (51) \\
\hline A-levels or equivalent & 468 & (25) & 204 & (23) & 186 & (24) \\
\hline Degree or postgraduate degree & 311 & (17) & 166 & (19) & 150 & (19) \\
\hline Travel mode & \multicolumn{2}{|c|}{$\mathbf{n}=2053$} & \multicolumn{2}{|c|}{$\mathbf{n}=913$} & \multicolumn{2}{|c|}{$\mathbf{n}=812$} \\
\hline Bicycle & 189 & (9) & 73 & (8) & 59 & (7) \\
\hline Bus or train & 127 & (6) & 62 & (7) & 57 & (7) \\
\hline Car & 923 & (45) & 357 & (39) & 322 & $(40)$ \\
\hline Foot & 814 & (40) & 421 & $(46)$ & 374 & (46) \\
\hline
\end{tabular}

participants were all in the 'consistent active travel' $(\mathrm{n}=18)$ or 'consistent passive travel' $(\mathrm{n}=16)$ groups. Excluding these participants from the analyses made no substantive difference to the findings (results not shown).

\section{Discussion}

In this population-based longitudinal study of 9-10 year old children, boys and girls who changed to an active mode of travel increased their total daily MVPA by an average of $9 \mathrm{~min}$ and $6 \mathrm{~min}$ respectively. This represents
$12 \%$ of boys' and $13 \%$ of girls' total daily time spent in MVPA at follow-up. The total daily MVPA of children who did not change their travel mode, or who changed to a passive mode, decreased over the same period. It should be noted however that boys and girls who changed to an active mode spent less time in MVPA (6 min/ day and $22 \mathrm{~min} /$ day, respectively) at baseline than children in the other exposure categories and may therefore have had greater potential to increase their physical activity levels. However, models were adjusted for students' baseline time spent in MVPA, to control for potential

Table 2 Unadjusted mean (SD) changes in total daily minutes spent in MVPA from baseline to follow-up

\begin{tabular}{|c|c|c|c|c|}
\hline \multirow{2}{*}{$\begin{array}{l}\text { Change in mode } \\
\text { of travel to } \\
\text { school between } \\
\text { baseline and one- } \\
\text { year follow-up }\end{array}$} & \multicolumn{2}{|c|}{ Boys $(n=332)$} & \multicolumn{2}{|c|}{ Girls $(n=480)$} \\
\hline & $\begin{array}{l}\text { Total daily time spent in } \\
\text { MVPA at baseline }\end{array}$ & $\begin{array}{l}\text { Change in total daily time } \\
\text { spent in MVPA a }\end{array}$ & $\begin{array}{l}\text { Total daily time spent in } \\
\text { MVPA at baseline }\end{array}$ & $\begin{array}{l}\text { Change in total daily time } \\
\text { spent in MVPA }\end{array}$ \\
\hline $\begin{array}{l}\text { Active to passive } \\
(n=50)\end{array}$ & $84(22)$ & $-17(81)$ & $67(14)$ & $-6(22)$ \\
\hline $\begin{array}{l}\text { Passive to active } \\
(n=75)\end{array}$ & $78(29)$ & $9(31)$ & $45(17)$ & $6(29)$ \\
\hline $\begin{array}{l}\text { Consistent active } \\
(n=358)\end{array}$ & $84(23)$ & $-5(27)$ & $66(26)$ & $-6(25)$ \\
\hline $\begin{array}{l}\text { Consistent } \\
\text { passive }(n=330)\end{array}$ & $84(24)$ & $-5(31)$ & $67(20)$ & $-4(26)$ \\
\hline
\end{tabular}

$\mathrm{n}=812,{ }^{a}$ time spent in MVPA is expressed as (1-year follow-up MVPA x 1000/1-year follow-up wear time) - (baseline MVPA x 1000/baseline wear time). 
Table 3 Unadjusted mean (SD) changes in weekday minutes spent in MVPA from baseline to follow-up

\begin{tabular}{|c|c|c|c|c|}
\hline \multirow{2}{*}{$\begin{array}{l}\text { Change in mode of } \\
\text { travel to school } \\
\text { between baseline } \\
\text { and one-year } \\
\text { follow-up }\end{array}$} & \multicolumn{2}{|c|}{ Boys $(n=332)$} & \multicolumn{2}{|c|}{ Girls $(n=480)$} \\
\hline & $\begin{array}{l}\text { Weekday time spent in } \\
\text { MVPA at baseline }\end{array}$ & $\begin{array}{l}\text { Change in weekday time } \\
\text { spent in MVPA a }\end{array}$ & $\begin{array}{l}\text { Weekday time spent in } \\
\text { MVPA at baseline }\end{array}$ & $\begin{array}{l}\text { Change in total daily time } \\
\text { spent in MVPA }\end{array}$ \\
\hline $\begin{array}{l}\text { Active to passive } \\
(n=50)\end{array}$ & $82(29)$ & $-12(20)$ & $68(19)$ & $-4(24)$ \\
\hline $\begin{array}{l}\text { Passive to active } \\
(\mathrm{n}=75)\end{array}$ & $80(24)$ & $8(28)$ & $65(16)$ & $10(28)$ \\
\hline $\begin{array}{l}\text { Consistent active } \\
(\mathrm{n}=358)\end{array}$ & $82(23)$ & $1(27)$ & $66(20)$ & $-3(24)$ \\
\hline $\begin{array}{l}\text { Consistent passive } \\
(\mathrm{n}=330)\end{array}$ & $83(23)$ & $-1(30)$ & $66(18)$ & $0(22)$ \\
\hline
\end{tabular}

$\mathrm{n}=812,{ }^{a}$ time spent in MVPA is expressed as (1-year follow-up MVPA x 1000/1-year follow-up wear time) - (baseline MVPA x 1000/baseline wear time).

regression to the mean. The results presented here, although using a more proximal outcome, support previous work by Cooper et al. who found that boys and girls who took up cycling to school during a 6-year period had better cardiorespiratory fitness than those who did not cycle to school at either baseline or follow-up [12].

For boys who changed to an active mode of travel, no significant association was observed with time spent in
MVPA on weekdays. However, a significant association was observed with daily time spent in MVPA over the entire week. These findings suggest that the observed association between active travel and overall physical activity may reflect the combined effect of the journeys themselves, spontaneous play during the journeys and an encouragement of active behaviour in other areas of children's lives [6]. It is also possible that increases in

Table 4 Associations between change in mode of travel to school and change in mean total daily minutes spent in MVPA

\begin{tabular}{|c|c|c|c|c|c|c|c|c|c|c|c|c|c|c|c|}
\hline \multirow[t]{2}{*}{ Variable } & \multicolumn{5}{|c|}{ Children $(n=772)$} & \multicolumn{5}{|c|}{ Boys $(n=314)$} & \multicolumn{5}{|c|}{ Girls $(n=458)$} \\
\hline & Coefficient & & $\% \mathrm{Cl}$ & & $\mathbf{P}$ & Coefficient & & $\% \mathrm{Cl}$ & & $\mathbf{P}$ & Coefficient & & $\% \mathrm{C}$ & & $\mathbf{P}$ \\
\hline \multicolumn{16}{|c|}{ Change in mode of travel (reference: consistent active) } \\
\hline Active to passive & -3.12 & -10.26 & to & 4.02 & 0.39 & -12.31 & -24.98 & to & 0.36 & 0.05 & 1.39 & -6.98 & to & 9.76 & 0.74 \\
\hline Passive to active & 12.08 & 6.14 & to & 18.02 & $<0.01$ & 11.78 & 1.16 & to & 22.41 & 0.03 & 11.92 & 5.01 & to & 18.84 & $<0.01$ \\
\hline Consistent passive & 1.98 & -1.63 & to & 5.60 & 0.28 & 1.27 & -4.95 & to & 7.50 & 0.68 & 2.76 & -1.56 & to & 7.10 & 0.21 \\
\hline \multicolumn{16}{|l|}{ Sex (reference: girl) } \\
\hline Boy & 10.75 & 7.11 & to & 14.40 & $<0.01$ & & & & & & & & & & \\
\hline \multicolumn{16}{|c|}{ Parental education (reference: none) } \\
\hline GCSE or equivalent & 7.56 & 0.21 & to & 14.90 & 0.04 & 3.73 & -9.85 & to & 17.33 & 0.59 & 11.01 & 2.54 & to & 19.47 & 0.01 \\
\hline A level or equivalent & 3.95 & -3.81 & to & 11.72 & 0.31 & -1.49 & -15.89 & to & 12.90 & 0.83 & 8.19 & -.69 & to & 17.09 & 0.07 \\
\hline $\begin{array}{l}\text { University/postgraduate } \\
\text { degree }\end{array}$ & 4.99 & -3.09 & to & 13.08 & 0.22 & 3.83 & -10.77 & to & 18.44 & 0.60 & 6.32 & -3.19 & to & 15.84 & 0.19 \\
\hline \multicolumn{16}{|c|}{ Location (reference: hamlet and isolated dwelling) } \\
\hline Village & 0.09 & -6.71 & to & 6.91 & 0.97 & -4.74 & -15.73 & to & 6.24 & 0.39 & 3.33 & -5.26 & to & 11.93 & 0.44 \\
\hline Town and fringe & -6.07 & -7.70 & to & 6.48 & 0.86 & 0.06 & -10.97 & to & 11.10 & 0.99 & -.68 & -9.87 & to & 8.50 & 0.88 \\
\hline Urban $>10 \mathrm{k}$ & -2.61 & -9.28 & to & 4.06 & 0.44 & -6.01 & -16.46 & to & 4.43 & 0.26 & 0.77 & -7.90 & to & 9.45 & 0.86 \\
\hline Age (years) & 2.93 & -2.68 & to & 8.56 & 0.30 & 1.05 & -8.98 & to & 11.09 & 0.83 & 3.88 & -2.74 & to & 10.52 & 0.25 \\
\hline BMI & -.30 & -.87 & to & 0.25 & 0.28 & -.53 & -1.67 & to & 0.61 & 0.36 & -1.05 & -.72 & to & 0.51 & 0.73 \\
\hline Route length (metres) & -.00 & -.00 & to & 0.00 & 0.15 & -.00 & -.00 & to & 0.00 & 0.48 & -.00 & -.00 & to & 0.00 & 0.25 \\
\hline \multicolumn{16}{|c|}{ Car ownership (reference: no car) } \\
\hline Owns one car & -4.99 & -14.20 & to & 4.21 & 0.28 & 6.24 & -8.85 & to & 21.35 & 0.41 & -16.79 & -28.52 & to & -5.06 & $<0.01$ \\
\hline Owns more than one car & -6.76 & -15.91 & to & 2.38 & 0.14 & 5.10 & -9.74 & to & 19.96 & 0.50 & -19.09 & -30.81 & to & -7.38 & $<0.01$ \\
\hline $\begin{array}{l}\text { Baseline time spent in } \\
\text { MVPA (min/day) }\end{array}$ & -.67 & -.74 & to & -.59 & $<0.01$ & -.67 & -.79 & to & -.55 & $<0.01$ & -.66 & -.76 & to & -.56 & $<0.01$ \\
\hline
\end{tabular}


Table 5 Associations between change in mode of travel to school and change in mean weekday minutes spent in MVPA

\begin{tabular}{|c|c|c|c|c|c|c|c|c|c|c|c|c|c|c|c|}
\hline \multirow[t]{2}{*}{ Variable } & \multicolumn{5}{|c|}{ Children $(n=772)$} & \multicolumn{5}{|c|}{ Boys $(n=314)$} & \multicolumn{5}{|c|}{ Girls $(n=458)$} \\
\hline & Coefficient & & $\% \mathrm{C}$ & & $\mathbf{P}$ & Coefficient & & $\% \mathrm{C}$ & & $\mathbf{P}$ & Coefficient & & $\% \mathrm{Cl}$ & & $\mathbf{P}$ \\
\hline \multicolumn{16}{|c|}{ Change in mode of travel (reference: consistent active) } \\
\hline Active to passive & -4.63 & -12.19 & to & 2.92 & 0.23 & -15.12 & -28.52 & to & -1.72 & 0.02 & 1.08 & -7.74 & to & 9.91 & 0.80 \\
\hline Passive to active & 10.81 & 4.51 & to & 17.11 & $<0.01$ & 7.66 & -3.65 & to & 18.97 & 0.18 & 11.95 & 4.67 & to & 19.24 & $<0.01$ \\
\hline Consistent passive & 1.96 & -1.87 & to & 5.79 & 0.31 & 0.28 & -6.28 & to & 6.84 & 0.93 & 3.78 & -.78 & to & 8.36 & 0.10 \\
\hline \multicolumn{16}{|l|}{ Sex (reference: girl) } \\
\hline Boy & 4.99 & 1.12 & to & 8.86 & 0.01 & & & & & & & & & & \\
\hline \multicolumn{16}{|c|}{ Parental education (reference: none) } \\
\hline GCSE or equivalent & 8.60 & 0.80 & to & 16.40 & 0.03 & 0.46 & -14.20 & to & 15.13 & 0.95 & 13.85 & 4.91 & to & 22.79 & $<0.01$ \\
\hline A level or equivalent & 5.02 & -3.20 & to & 13.26 & 0.23 & -5.62 & -21.11 & to & 9.86 & 0.47 & 11.91 & 2.53 & to & 21.29 & 0.01 \\
\hline $\begin{array}{l}\text { University/postgraduate } \\
\text { degree }\end{array}$ & 7.40 & -1.18 & to & 16.00 & 0.09 & 2.19 & -13.58 & to & 17.98 & 0.78 & 10.51 & 0.47 & to & 20.56 & 0.04 \\
\hline \multicolumn{16}{|c|}{ Location (reference: hamlet and isolated dwelling) } \\
\hline Village & -1.15 & -8.48 & to & 6.16 & 0.75 & -1.80 & -13.85 & to & 10.24 & 0.76 & 0.94 & -8.14 & to & 10.04 & 0.83 \\
\hline Town and fringe & -1.27 & -9.12 & to & 6.58 & 0.75 & 2.79 & -9.59 & to & 15.18 & 0.65 & -3.92 & -13.75 & to & 5.89 & 0.43 \\
\hline Urban $>10 \mathrm{k}$ & -.23 & -7.37 & to & 6.90 & 0.94 & -.47 & -11.72 & to & 10.78 & 0.93 & 1.62 & -7.55 & to & 10.81 & 0.72 \\
\hline Age (years) & 1.24 & -4.75 & to & 7.23 & 0.68 & 0.86 & -9.80 & to & 11.53 & 0.87 & 0.64 & -6.36 & to & 7.66 & 0.85 \\
\hline BMI & -.36 & -.96 & to & .22 & 0.22 & -.17 & -1.39 & to & 1.05 & 0.78 & -.37 & -1.02 & to & 0.27 & 0.26 \\
\hline Route length (metres) & -.00 & -.00 & to & .00 & 0.65 & 0.00 & -.00 & to & 0.00 & 0.87 & -.00 & -.00 & to & 0.00 & 0.42 \\
\hline \multicolumn{16}{|c|}{ Car ownership (reference: no car) } \\
\hline Owns one car & 1.60 & -8.14 & to & 11.36 & 0.74 & 6.39 & -9.73 & to & 22.53 & 0.43 & -5.36 & -17.75 & to & 7.02 & 0.39 \\
\hline Owns more than one car & 0.12 & -9.58 & to & 9.82 & 0.98 & 4.55 & -11.37 & to & 20.49 & 0.57 & -6.98 & -19.36 & to & 5.39 & 0.26 \\
\hline $\begin{array}{l}\text { Baseline time spent in } \\
\text { MVPA (min/day) }\end{array}$ & -.27 & -.35 & to & -.18 & $<0.01$ & -.27 & -.39 & to & -.14 & $<0.01$ & -.26 & -.37 & to & -.15 & $<0.01$ \\
\hline
\end{tabular}

95\% Cl: 95\% confidence interval.

active travel may reflect a change in travel mode preference resulting from a more general increase in physical activity; in other words, children who become more active in general may then choose to travel to school by active means. Further analyses using multiple time points are needed to investigate these potential causal pathways.

Children who consistently used either an active or a passive mode of travel recorded decreases in MVPA over the one-year study period, as did children who changed from an active to a passive mode. This suggests that while taking up an active mode of travel may negate the downward trend in MVPA that is typically seen in this age group $[14,17]$, continuing active travel is not sufficient to do so. The decline in MVPA seen among children who remained active travellers highlights a need for interventions that prevent a decline in physical activity in other areas of children's lives, for example during and after school, as well as interventions to promote active travel.

In this study only $9.2 \%$ of pupils changed to an active mode of travel, while $40.6 \%$ consistently used passive modes. In 2005, $43 \%$ of UK children were driven to school [4]. Interventions that promote active modes of travel to school therefore have the potential to increase the activity levels of large numbers of pupils, which may have important public health implications $[1,18]$. However, a recent systematic review found that to date, interventions promoting active travel to school have produced only small effects, suggesting a need for further research as to how best to achieve such behaviour change in practice [19].

Two-level regression models showed that parental education - an indicator of socioeconomic status (SES) - predicted changes in girls' time spent in MVPA but not boys'. Since boys participate in more active play in their free time than girls [20], it is possible that parents encourage their daughters, or girls choose, to accumulate MVPA in other ways such as organised sports. The costs associated with participating in organised sports (such as those of equipment and membership fees) might contribute to explaining why parental SES appears to be an important influence on girls' time spent in MVPA and not associated with boys'. 


\section{Strengths and limitations}

Strengths of this study include its prospective design, the use of objective measures of physical activity and that it was conducted in a large population-based sample of UK primary school children. The one year interval separating baseline and follow-up data collection ensured seasonally matched data, thereby reducing the risk of artefactual changes in either usual travel behaviour or measured physical activity attributable to different weather conditions at the two time points. It also provided sufficient time to result in changes to children's usual travel behaviour. However, despite the prospective design, it remains unclear whether children become more physically active and then changed to an active mode of travel, or vice versa. A longitudinal dataset including measurement at three or more time points or a controlled intervention study would be needed to answer this question with confidence.

Although the analysis sample comprised approximately one-third of the pupils recruited at baseline, we found no significant differences between the characteristics (sex, BMI, urban rural/status, parental education or baseline MVPA) of pupils included in and excluded from the analysis. However, we have previously shown that in comparison to the Norfolk population a smaller proportion of obese children took part in the SPEEDY study, and that the demographic profile of the county of Norfolk (with only $3.8 \%$ non-white children) is not representative of the whole of the UK [13].

The measure of travel mode was relatively crude and did not allow multi-modal trips or the daily breakdown of travel behaviour to be ascertained. Moreover, to our knowledge there is no published validation of questions to ascertain 'usual travel mode' in children. However, similar measures have been used in previous studies examining the association between travel mode and physical activity in children $[8,21]$. Furthermore, an insufficient proportion (6\%) of pupils used public transport at baseline to allow public transport to be treated as a separate category. Consequently, if we had disaggregated travel mode further into car, public transport, walking and cycling our statistical models would had been underpowered to detect associations. As in previous studies, public transport was therefore combined with passive travel [22]. Although travelling by public transport usually includes some walking, school bus services in the UK often pick up pupils close to their homes and it is therefore reasonable to assume that these journeys might have included relatively little active travel. In support of this assumption, van Sluijs et al. found that UK children who walked to school had significantly higher average weekly accelerometer counts per minute and total minutes of MVPA than those classified as using the car or public transport to travel to school [23].
Moreover, removing pupils who used public transport from the current analyses made no substantive differences to the findings (results not shown). Distance from home to school has consistently been found to be associated with mode of travel to and from school [24,25]. Although network distance was included as a covariate in analysis, it was not possible to stratify the analysis by this measure owing to small cell sizes.

Accelerometers as used in this study are calibrated to record ambulatory activity (hip movement) and therefore underestimate the intensity of physical activity undertaken whilst cycling. In this study only $9 \%$ and $7 \%$ of pupils reported cycling to school at baseline and follow-up respectively, so the influence of this limitation of measurement is likely to be small. Criteria for classifying accelerometer non-wear time vary within the literature [26,27]. For the present analysis 10 minutes of continuous zero counts were used to define non-wear. It appears reasonable to assume that 9-10 year old children are unlikely to remain sufficiently still to register no movement on an accelerometer for more than 10 minutes when awake, and this criterion has been applied in previous studies [26,28].

\section{Conclusion}

Taking up active travel to school is associated with increased levels of MVPA in primary school children. This study provides further evidence that promoting active travel to school may have a role in contributing to increasing physical activity levels in children.

\section{Competing interest}

The authors declare that there are no conflicts of interest.

\section{Authors' contributions}

A.J, K.C, S.J.G and E.S designed the SPEEDY study and coordinated its implementation. L.S conducted the statistical analyses and drafted the manuscript. A.J, K.C, S.J.G, E.S, D.O and S.S assisted in interpreting the statistical analyses and drafting the manuscript. All authors read and approved the final manuscript.

\section{Acknowledgments}

We thank the schools, pupils and parents for their participation in the SPEEDY study. We also thank everyone who helped with the data collection and Norfolk Children's Services for their invaluable input and support. The SPEEDY study is funded by the National Prevention Research Initiative (http://www.npri.org.uk), consisting of the following Funding Partners: British Heart Foundation; Cancer Research UK; Department of Health; Diabetes UK; Economic and Social Research Council; Medical Research Council; Health and Social Care Research and Development Office for the Northern Ireland; Chief Scientist Office, Scottish Government Health Directorates; Welsh Assembly Government and World Cancer Research Fund.

LS and SS are supported by the Engineering and Physical Sciences Research Council (grant reference EP/G00059X/1). DO, SG and EvS are supported by the Medical Research Council [Unit Programme number U106179474] and the work of KC, SG, AJ and DO is also supported by the Centre for Diet and Activity Research (CEDAR), a UKCRC Public Health Research Centre of Excellence. Funding from the British Heart Foundation, Economic and Social Research Council, Medical Research Council, National Institute of Health Research (NIHR) and the Wellcome Trust, under the auspices of the UK Clinical Research Collaboration, is gratefully acknowledged. The views 
expressed in this publication are those of the authors and not necessarily those of the Department of Health or other funders.

\section{Author details}

'MRC Epidemiology Unit, Institute of Metabolic Science, Addenbrooke's Hospital, Box 285, Cambridge CB2 0QQ, UK. ${ }^{2}$ UKCRC Centre for Diet and Activity Research (CEDAR), Institute of Public Health, Forvie Site, Robinson Way, Cambridge CB2 OSR, UK. ${ }^{3}$ School of Environmental Sciences, University of East Anglia, Norwich NR4 7JT, UK.

Received: 29 March 2012 Accepted: 9 November 2012 Published: 21 November 2012

\section{References}

1. Strong WB, Malina RM, Blimkie CJR, Daniels SR, Dishman RK, Gutin B, Hergenroeder AC, Must A, Nixon PA, Pivarnik JM, et al: Evidence based physical activity for school-age youth. J Pediatr 2005, 146:732-737.

2. Ortega FB, Ruiz JR, Castillo MJ, Sjostrom M: Physical fitness in childhood and adolescence: a powerful marker of health. Int J Obes 2008, 32:1-11.

3. Lubans DR, Boreham CA, Kelly P, Foster CE: The relationship between active travel to school and health-related fitness in children and adolescents: a systematic review. Int J Behav Nutr Phys Act 2011, 8:5.

4. Department for Transport: Transport Trends. London: TSO Publications; 2006.

5. Faulkner GE, Buliung RN, Flora PK, Fusco C: Active school transport, physical activity levels and body weight of children and youth: a systematic review. Prev Med 2009, 48:3-8.

6. Lee MC, Orenstein MR, Richardson MJ: Systematic review of active commuting to school and childrens physical activity and weight. J Phys Act Health 2008, 5:930-949.

7. Rosenberg DE, Sallis JF, Conway TL, Cain KL, McKenzie TL: Active transportation to school over 2 years in relation to weight status and physical activity. Obesity (Silver Spring) 2006, 14:1771-1776.

8. Cooper AR, Wedderkopp N, Wang H, Andersen LB, Froberg K, Page AS Active travel to school and cardiovascular fitness in Danish children and adolescents. Med Sci Sports Exerc 2006, 38:1724-1731.

9. Panter J, Jones A, Van Sluijs E, Griffin S: The influence of distance to school on the associations between active commuting and physical activity. Pediatr Exerc Sci 2011, 23:72-86.

10. van Sluiis E, McMinn A, Griffin S: Effectivness of interventions to promote physical activity in children and adolescents: systematic review of controlled trials. BMJ 2007, 335:703.

11. Fremeaux A, Mallam K, Metcalf B, Hosking J, Voss L, Wilkin T: The impact of school-time activity on total physical activity: the activitystat hypothesis. Int J Obes 2011, 35:1277-1283.

12. Cooper AR, Wedderkopp N, Jago R, Kristensen PL, Moller NC, Froberg K, Page AS, Andersen LB: Longitudinal associations of cycling to school with adolescent fitness. Prev Med 2008, 47:324-328.

13. van Sluijs EM, Skidmore PM, Mwanza K, Jones AP, Callaghan AM, Ekelund U, Harrison F, Harvey I, Panter J, Wareham NJ, et al: Physical activity and dietary behaviour in a population-based sample of British 10-year old children: the SPEEDY study (Sport, Physical activity and Eating behaviour: environmental Determinants in Young people). BMC Public Health 2008, 8:388.

14. Corder K, van Sluijs EM, Ekelund U, Jones AP, Griffin SJ: Changes in children's physical activity over 12 months: longitudinal results from the SPEEDY study. Pediatrics 2010, 126:e926-e935.

15. Ekelund U, Sardinha LB, Anderssen SA, Harro M, Franks PW, Brage S, Cooper AR, Andersen LB, Riddoch C, Froberg K: Associations between objectively assessed physical activity and indicators of body fatness in 9- to 10-y-old European children: a population-based study from 4 distinct regions in Europe (the European Youth Heart Study). Am J Clin Nutr 2004, 80:584-590.

16. Panter JR, Jones AP, Van Sluiis EM, Griffin SJ: Neighborhood, route, and school environments and children's active commuting. Am J Prev Med 2010, 38:268-278.

17. Kimm SY, Glynn NW, Kriska AM, Barton BA, Kronsberg SS, Daniels SR, Crawford PB, Sabry ZI, Liu K: Decline in physical activity in black girls and white girls during adolescence. N Engl I Med 2002, 347:709-715.

18. Telama R, Yang X, Viikari J, Valimaki I, Wanne O, Raitakari O: Physical activity from childhood to adulthood: a 21-year tracking study. Am J Prev Med 2005, 28:267-273.
19. Chillon P, Evenson KR, Vaughn A, Ward DS: A systematic review of interventions for promoting active transportation to school. Int I Behav Nutr Phys Act 2011, 8:10.

20. Fox K, Riddoch C: Charting the physical activity patterns of contemporary children and adolescents. Proc Nutr Soc 2000, 59(4):497-504.

21. Cooper AR, Andersen LB, Wedderkopp N, Page AS, Froberg K: Physical activity levels of children who walk, cycle, or are driven to school. Am J Prev Med 2005, 29:179-184.

22. Smith $L$, Sahlqvist $S$, Ogilvie $D$, Jones A, Griffin $S$, van Sluijs E: Is active travel to non-school destinations associated with physical activity in primary school children? Prev Med 2012, 10:1016. j.ypmed.2012.01.006.

23. van Sluijs E, Fearne V, Mattocks C, Riddoch C, Griffin S, Ness A: The contribution of active travel to children's physical activity levels: crosssectional results from the ALSPAC study. Prev Med 2009, 48:519-524

24. Timperio A, Ball K, Salmon J, Roberts R, Giles-Corti B, Simmons D, Baur LA, Crawford D: Personal, family, social, and environmental correlates of active commuting to school. Am J Prev Med 2006, 30:45-51.

25. Nelson NM, Foley E, O'Gorman DJ, Moyna NM, Woods CB: Active commuting to school: How far is too far? Int I Behav Nutr Phys Act 2008, 5:1.

26. Eiberg S, Hasslestrom H, Gronfeldt V, Froberg K, Svensson J, Andersen L: Maximum oxygen uptake and objectivley measured physical activity in Danish children 6-7 years of age: The Copenhagen school child intervention study. Br J Sports Med 2005, 39:725-730.

27. Van Coervering P, Harnak K, Schmitz J, Fulton D, Galuska S: Feasibility of using accelerometers to measure physical activity in young adolescents. Med Sci Sports Exerc 2005, 37:867-871.

28. Mattocks C, Ness A, Leary S, Tilling K, Blair S, Shield J, Deere K, Saunders J, Kirkby J, Smith G, Wells J, Wareham N, Reilly J, Riddoch C: Use of accelerometers in a large field-based study of children: protocols, design issues, and effects on precision. J Phys Act Health 2008, 1:S98-S111.

doi:10.1186/1479-5868-9-134

Cite this article as: Smith et al:: Is a change in mode of travel to school associated with a change in overall physical activity levels in children? Longitudinal results from the SPEEDY study. International Journal of Behavioral Nutrition and Physical Activity 2012 9:134.

\section{Submit your next manuscript to BioMed Central and take full advantage of:}

- Convenient online submission

- Thorough peer review

- No space constraints or color figure charges

- Immediate publication on acceptance

- Inclusion in PubMed, CAS, Scopus and Google Scholar

- Research which is freely available for redistribution 